\title{
The potential of follicle-stimulating hormone peptide-modified triptolide-loaded nanoparticles to induce a mouse model of premature ovarian insufficiency
}

\author{
This article was published in the following Dove Press journal: \\ International Journal of Nanomedicine \\ 7 April 2015 \\ Number of times this article has been viewed
}

\author{
Xiu-Ying Chen ${ }^{1-3}$ \\ Wu-Lian Chen ${ }^{4}$ \\ Min $\mathrm{Ma}^{\mathrm{l-3}}$ \\ Chao $\mathrm{Gu}^{1,2}$ \\ Xi-Rong Xiao ${ }^{1,2}$ \\ Bin $\mathrm{Li}^{1,2}$
}

'Obstetrics and Gynecology Hospital, Fudan University, ${ }^{2}$ Department of Obstetrics and Gynecology of Shanghai Medical College, Fudan University, ${ }^{3}$ Shanghai Key Laboratory of Female Reproductive Endocrine Related Diseases, ${ }^{4}$ State Key Laboratory of Molecular Engineering of Polymers, Department of Macromolecular Science, Fudan University, Shanghai, People's Republic of China

\begin{abstract}
The use of triptolide (TP) is limited by its poor water solubility and severe toxicity. In this study, we developed an active drug delivery system (TP-loaded nanoparticles) that could help improve the water solubility of TP and decrease its toxicity. Then, we investigated whether TP-loaded nanoparticles could be used to establish a novel premature ovarian insufficiency mouse model. The mice treated with TP-loaded nanoparticles for 35 days displayed normal growth, decreased serum antimullerian hormone, prominent ovarian fibrosis and vacuolar changes, fewer follicles and corpus lutea, increased collapsed oocytes and follicle apoptosis, and sterility. In conclusion, this model appears to show the reproductive characteristics associated with premature ovarian insufficiency in women and will allow us to study the mechanism of the effects of traditional Chinese medicine on gonadal toxicity.
\end{abstract}

Keywords: peptide, nanoparticles, drug delivery, premature ovarian insufficiency, animal model

\section{Introduction}

Triptolide (TP) is a key active diterpenoid triepoxide extracted from the traditional Chinese medicinal plant, Tripterygium wilfordii Hook F (TWHF), which has been used for centuries to treat autoimmune and inflammatory diseases such as rheumatoid arthritis, systemic lupus erythematosus, psoriasis, ankylosing spondylitis, nephritis, as well as organ or tissue transplantation. ${ }^{1-3}$ Many experimental studies have demonstrated that TP possesses a unique pharmacological spectrum of anti-inflammatory, anticancer, and immunosuppressive activity. ${ }^{1-3}$ TWHF can greatly affect the female reproductive system, causing irregular menstruation, amenorrhea, and even premature ovarian failure. ${ }^{4} \mathrm{TP}$ can cause infertility in male rats and also induce adverse effects on the rodent female reproductive system that are similar to the phenotype of ovarian insufficiency. ${ }^{5}$ Its reproductive toxicity in females may be mainly caused by its disruption of cyclic adenosine monophosphate/protein kinase A-mediated expression of estrogen and progesterone synthesis enzymes, leading to reduced estradiol and progesterone synthesis, and also to reproductive dysfunction. ${ }^{6,7}$ Its side effects on reproductive systems make it a good candidate for creating a mouse model of premature ovarian insufficiency (POI). Nevertheless, owing to its poor water solubility and severe toxicity, its use in experiments has been limited.

Our aim was to specifically deliver TP to the targeted organ, the ovary, and avoid severe toxicity. To this end, we aimed to design an active targeted drug delivery system
Correspondence: Bin Li

Obstetrics and Gynecology Hospital,

Fudan University, 419 Fang-Xie Road,

Shanghai 2000I I, People's Republic of China

Tel +862163455050

Fax +86216345 5090

Email libin782@I26.com 
toward the ovary. Our strategy consisted of modifying TP with drug-delivering nanoparticles by the specific binding of small molecules to target certain cell receptors. We chose follicle-stimulating hormone (FSH) receptor (FSHR) as the target site due to its high expression on the granulosa cells in the ovary. Several binding domains of FSHR have been clearly identified, to which FSH- $\beta$-(33-53) has the strongest binding capacity. ${ }^{8,9}$ The sequence, YTRDLVYKDPARPNTQKVCTF (the structure is shown in Figure 1A), of the mouse FSH- $\beta$ chain corresponds to human FSH- $\beta$ (33-53), according to the UniProtKB/Swiss-Prot database. As TP is fat soluble, we considered an amphiphilic block copolymer as a promising drug-delivering nanoparticle. ${ }^{10}$ Hydrophobic poly(lactic acid) (PLA) nanoparticles were suitable for accommodating the delivery of TP. Moreover, the hydrophilic-biocompatible material, polyethylene glycol (PEG), was the ideal approach to improve the drug nanoparticle's water solubility. Therefore, we investigated FSH- $\beta$ peptide-modified nanoparticles containing TP (TP-loaded nanoparticles) to ensure specific drug delivery to the ovary to establish a mouse model of POI.

\section{Materials and methods}

\section{Animals}

Healthy female Kunming mice (6 weeks of age) and female C57BL/6 mice (5 weeks of age) were obtained from the Laboratory Animal Center of Fudan University (Shanghai, People's Republic of China). All experimental animals were housed in groups of five per wire cage and kept under standard laboratory conditions (12 hours of light, 12 hours of dark; $25^{\circ} \mathrm{C}$ ). All the mice were kept for at least 5 days to acclimatize before the experiments begun. All mice treatments were approved by the Experimental Animal Ethical Committee of Fudan University.

\section{Drugs and chemicals}

TP (purity, >98\%) was purchased from the National Institutes for Food and Drug Control (Beijing, People's Republic of China). Toluene (99\%; Sigma-Aldrich Co., St Louis, MO, USA) was refluxed with a sodium bead/ benzophenone complex and distilled until the solution turned purple. Dilactide was purchased from J\&K Chemicals Ltd. (Shanghai, People's Republic of China),


Figure I The structures of the nanomaterials.

Notes: (A) FSH- $\beta$ peptide “YTRDLVYKDPARPNTQKVCTF”; (B) GPC traces for (a) PEG-b-PLA and (b) Mal-PEG-b-PLA; (C) 'H NMR spectra of Mal-PEG-b-PLA; (D) 'H NMR spectra of FSH-Mal-PEG-b-PLA.

Abbreviations: MW, molecular weight; FSH, follicle-stimulating hormone; GPC, gel permeation chromatography; PEG, polyethylene glycol; PLA, poly(lactic acid); Mal, maleimide; NMR, nuclear magnetic resonance. 
recrystallized three times from ethyl acetate, and stored under vacuum prior to use. PEG methyl ether (PEG-OH; Sigma-Aldrich Co.) (99\%; molecular weight [MW] =5,000 g/mol), maleimide-PEG-hydroxy (Mal-PEG-OH) (America; $\mathrm{MW}=5,000 \mathrm{~g} / \mathrm{mol} ;>95 \%$ ), and stannous 2-ethylhexanoate $\left(\mathrm{Sn}[\mathrm{Oct}]_{2}\right)$ (99\%; Sigma-Aldrich Co.) were used as received without further purification. FSH- $\beta$ peptide (YTRDLVYKDPARPNTQKVCTF) was synthesized via solid-phase peptide synthesis by ChinaPeptides Co., Ltd. (Shanghai, People's Republic of China), purified by high-performance liquid chromatography (HPLC), and identified by mass spectrometry (MS). Its MW was $2,515.89$, and the purity of the peptide was $>95 \%$.

\section{Synthesis of PEG-b-PLA and Mal-PEG-b- PLA amphiphilic diblock copolymer}

A PEG-b-PLA and Mal-PEG-b-PLA amphiphilic diblock copolymer was prepared by the ring open polymerization of lactic acid (LA) using PEG-OH and Mal-PEG-OH as the initiator. In a typical procedure, a dry $50 \mathrm{~mL}$ Schlenk flask (flame-dried under vacuum prior to use) was charged with PEG-OH (1.0 g; $0.2 \mathrm{mmol}$ ) (Mal-PEG-OH [0.25 g; 0.05 $\mathrm{mmol})$ ), LA (4.0 g; $27.8 \mathrm{mmol})$ or (1.0 g; $6.95 \mathrm{mmol})$ and $\mathrm{Sn}(\mathrm{Oct})_{2}(125 \mathrm{mg})$. Then, the mixture was dried in vacuo for 4 hours followed by immersing in an oil bath at $160^{\circ} \mathrm{C}$. The polymerization lasted 4 hours and was terminated by immersing the flask into liquid $\mathrm{N}_{2}$. Then, the mixture was diluted with tetrahydrofuran (THF) and precipitated into an excess of cold mixture solution (ether: hexane $=1: 1, \mathrm{~V}: \mathrm{V}$ ). The previously mentioned dissolution-precipitation cycle was repeated three times. Finally, the final product was dried in vacuo overnight, yielding a white solid.

\section{Synthesis of FSH-Mal-PEG-b-PLA}

Typically, Mal-PEG-b-PLA (124 mg; 0.005 mmol), FSH peptide (13.6 mg; $0.01 \mathrm{mmol}$ ) and N,N-dimethylformamide $(10 \mathrm{~mL})$ were added to a $50 \mathrm{~mL}$ flask. The mixture was stirred at room temperature for 24 hours. Then, the solution was transferred to a dialysis bag with an MW cut-off of 14,000 Da to remove the residual FSH. Finally, a white solid was obtained by freeze-drying.

\section{TP drug loading}

Mal-PEG-b-PLA(10 mg), PEG-b-PLA (80 mg), and TP (3.0 mg) were dissolved in a $10 \mathrm{~mL}$ solvent (acetone: ethanol $=3: 2, \mathrm{~V}: \mathrm{V}$ ), then $10 \mathrm{~mL}$ of deionized water was added dropwise under vigorous stirring. After equilibrating for 4 hours under stirring, the solvent was volatilized at room temperature. The solution was then filtered through a $0.45 \mu \mathrm{m}$ Millipore filter
(EMD Millipore, Billerica, MA, USA) to remove free TP, and it was finally lyophilized.

\section{Nanomaterial measurements}

${ }^{1} \mathrm{H}$ nuclear magnetic resonance spectra were recorded on a Bruker Avance 500 spectrometer using $\mathrm{CDCl}_{3}$ as the solvent, and trimethylsilane was used as the internal standard. The MW and MW distribution were determined by gel permeation chromatography (GPC). The GPC was performed in THF at $35^{\circ} \mathrm{C}$ with an elution rate of $1.0 \mathrm{~mL} /$ minute on an Agilent 1100 machine equipped with a G1310A pump, a G1362A refractive index detector, and a G1314A variable-wavelength detector. Polystyrene standard samples were employed for the GPC calibration.

\section{Characteristics of TP-loaded nanoparticles}

Transmission electron microscopy images were obtained on a JEOL JEM $2100 \mathrm{~F}$ transmission electron microscope, and samples for transmission electron microscopy measurements were prepared by casting one drop of sample aqueous solution on carbon copper grids. The size distribution and zeta potential of the micelles were measured by dynamic light scattering using a Malvern autosizer 4700 instrument. TPloaded nanoparticles were dissolved in acetonitrile, and the content of TP in the nanoparticles was determined by HPLC using a reversed-phase column (LiChrospher Octadecylsilyl $\mathrm{C} 18 ; 250 \mathrm{~mm} \times 4.6 \mathrm{~mm}, 5 \mu \mathrm{m})$. The gradient mobile phase consisted of a mixture of methanol and water, and the flow rate was $1.0 \mathrm{~mL} / \mathrm{minute}$. The column effluent was detected at $218 \mathrm{~nm}$, and the column temperature was $30^{\circ} \mathrm{C}$. Drug-loading efficiency (DL \%) and encapsulation efficiency (EE \%) were calculated according to the following equations:

$$
\begin{gathered}
\mathrm{DL} \%=\mathrm{W} 1 /(\mathrm{W} 1+\mathrm{W} 2) \times 100 \% ; \\
\mathrm{EE} \%=\mathrm{W} 1 / \mathrm{W} 3 \times 100 \% .
\end{gathered}
$$

(W1: the weight of drug incorporated in the nanoparticles; W2: the weight of the initial feeding polymer; W3: the weight of the initial feeding drug.)

\section{Acute toxicity study and $\mathrm{LD}_{50}$}

After acclimatization, 100 Kunming mice were randomly divided into ten groups, five of which were treated with $\mathrm{TP}$ at these doses: $0.51 \mathrm{mg} / \mathrm{kg} ; 0.64 \mathrm{mg} / \mathrm{kg} ; 0.80 \mathrm{mg} / \mathrm{kg}$; $1.00 \mathrm{mg} / \mathrm{kg}$; and $1.25 \mathrm{mg} / \mathrm{kg}$. Another five groups were treated with TP-loaded nanoparticles at $0.80 \mathrm{mg} / \mathrm{kg}$, $1.00 \mathrm{mg} / \mathrm{kg}, 1.25 \mathrm{mg} / \mathrm{kg}, 1.56 \mathrm{mg} / \mathrm{kg}$, and $1.95 \mathrm{mg} / \mathrm{kg}$. The drug concentration was calculated according to TP content. 
All the animals were administered with a single dose by tail vein injection and were observed carefully for 14 days. We recorded any behavioral changes, toxicity symptoms, and deaths. Body weight was measured on days $0,3,7$, and 14 .

\section{Mouse model induction and fertility evaluation}

All the C57BL/6 mice were divided into three groups: control group (number $[n]=12)$; TP group $(n=12)$; and TP-loaded nanoparticle group $(n=13)$. Mice in the TP and TP-loaded nanoparticle groups were treated with $0.4 \mathrm{mg} / \mathrm{kg}$ (according to TP content) every day via intraperitoneal injection for 35 days. Mice in the control group were given the same volume of sterile water. The day after the last dose, six mice in the control group and TP group and 13 mice in the TPloaded nanoparticle group were put with mature male C57 mice (age: 9-10 weeks). For mating, female and male mice were housed as individual pairs for 15 days. A copulatory plug was observed if the female was pregnant, and this day was counted as day 0 of gestation. Vaginal cytology was continued to ensure whether the mice were pregnant, and a dramatic weight gain or visual inspection usually occurred at days $10-12$ of gestation.

\section{Serum AMH detection}

Blood samples were collected and centrifuged at 4,000 rpm for 10 minutes to separate serum and plasma. Then, serum was measured by an antimullerian hormone (AMH) enzymelinked immunosorbent assay kit (AOGMA biosciences company, Shanghai, People's Republic of China), using 96-well plates.

\section{Ovarian histomorphology}

After mating, all the mice were anesthetized by intraperitoneal injection with a $10 \%$ chloral hydrate solution $(0.3 \mathrm{~mL} / 100 \mathrm{~g})$. When the ovaries were fixed in $4 \%$ paraformaldehyde for 48 hours, they were embedded in paraffin, serially sectioned at $4 \mu \mathrm{m}$, and stained in hematoxylin and eosin for microscopic observation.

\section{Follicle cell apoptosis detection by TUNEL assay}

Apoptotic cells in ovarian tissue sections were identified by the In Situ Cell Death Detection Kit (Hoffman-La Roche Ltd., Basel, Switzerland) according to the manufacturer's protocol. The main procedures were as follows. After deparaffinization and rehydration, all the slides were incubated in freshly prepared $0.1 \%$ Triton $^{\mathrm{TM}} \mathrm{X}-100$ permeabilization solution with $0.1 \%$ citrate buffer for 8 minutes. We then immersed the slides for 30 minutes at room temperature in Tris- $\mathrm{HCl}$,

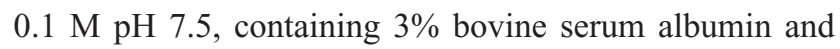
$20 \%$ normal bovine serum. The slides were rinsed twice with phosphate buffered saline after every procedure. We added $50 \mu \mathrm{L}$ of terminal deoxynucleotidyl transferase dUTP nick end labeling (TUNEL) reaction mixture to the section and incubated for 1 hour at $37^{\circ} \mathrm{C}$, and we then added $20 \mu \mathrm{L}$ of $4^{\prime}, 6$-diamidino-2-phenylindole (DAPI) to the section and incubated for 3 minutes. Finally, we rinsed the slides and evaluated the section under a fluorescence microscope.

\section{Statistical analysis}

All the data were analyzed using SPSS software, version 16.0 (IBM Corporation, Armonk, NY, USA), and the data are expressed as the mean \pm standard deviation. The differences in body weights and serum AMH levels were analyzed using one-way analysis of variance. The differences in mating efficiency and fertility outcome were analyzed using the chi-square test. A $P$-value $<0.05$ was defined as statistically significant. $\mathrm{LD}_{50}$ (lethal median dose) and its $95 \%$ credibility were calculated according to the Bliss method.

\section{Results \\ Characterization of drug-delivering nanoparticles}

The amphiphilic diblock copolymer was obtained by the ring open polymerization of LA using PEG-OH or Mal-PEG-OH as the initiator. The MW and its distribution of PEG-b-PLA and Mal-PEG-b-PLA were determined by GPC using THF as the eluent, revealing a Mn of 24.5 KDa and $21.8 \mathrm{KDa}$, and MW/Mn of 1.50 and 1.49, respectively (Figure 1B). Their degrees of polymerization were 259 and 243 , respectively. Utilizing the maleimide group as an active reaction site, the FSH- $\beta$ peptide with a sulfydryl group could be covalently coupled to the amphiphilic copolymer, Mal-PEG-b-PLA. As observed from Figures $1 \mathrm{C}$ and D, the peak representing the maleimide group at $6.70 \mathrm{ppm}$ completely disappeared after the reaction, which indicated that the FSH- $\beta$ peptide was successfully covalent to Mal-PEG-b-PLA. PEG is hydrophilic and PLA is hydrophobic, and thus the resulting PEG-b-PLA and FSH-Mal-PEG-b-PLA were amphiphilic and could self-assemble into micelles with hydrophobic PLA as the core and the hydrophilic PEG side chain as the shell in an aqueous solution. Meanwhile, TP was the highly hydrophobic drug and could be entrapped in the hydrophobic core of amphiphilic copolymer micelles by a hydrophobichydrophobic interaction. The micelles were spherical and had 
an average diameter of approximately $100 \mathrm{~nm}$, which was also confirmed by the dynamic light scattering measurement (Figure 2). The polydispersity index of the micelles was 0.12. TP was separated from impurities according to HPLC detection, and the dissolvent acetonitrile had no interference to it (Figure 3A and B). Furthermore, the ultraviolet absorption of copolymer was not seen in HPLC due to the lack of conjugated structure in the copolymer. After acetonitrile and methanol were eliminated, the curve was consistent with a TP standard (Figure 3C). The appearance time of the prominent peak was 13.4 minutes. The drug-loading and encapsulation efficiencies were $3.33 \%$ and $99.26 \%$, respectively (Table 1 ), based on the TP standard curve.

\section{TP-loaded nanoparticles reduce TP acute toxicity}

The toxicity behaviors were observed shortly after drug administration, and they included activity reduction, crouching, anorexia, emaciation, drowsiness, and asthenia. No dead mice were found by 12 hours, but deaths were concentrated between 24-48 hours after treatment. Few mice died after 7 days. As shown in Table 2, the mortality increased progressively as the dose increased from $0.64 \mathrm{mg} / \mathrm{kg}$ to $0.80 \mathrm{mg} / \mathrm{kg}$ in the TP group, and all the mice died when they received the dose of $1.25 \mathrm{mg} / \mathrm{kg}$. The mortality increased from $1.00 \mathrm{mg} / \mathrm{kg}$ to $1.25 \mathrm{mg} / \mathrm{kg}$ in the TP-loaded nanoparticle group, and its $\mathrm{LD}_{50}$ value was $63 \%$ higher than that of TP.

\section{Growth of mice}

All the mice grew at the same speed. There were no significant differences in body weight between the groups
(Figure 4). No apparent toxicity manifestation or death was found due to TP or TP-loaded nanoparticle treatment.

\section{Effects on serum AMH level}

TP-loaded nanoparticles significantly decreased AMH levels in serum compared with the vehicle control and TP groups $(P<0.01)$. However, treatment with TP did not alter AMH when compared with control (Figure 5).

\section{Fertility outcome}

To determine the effects on reproductive outcomes at the end of dosing, C57BL/6 female mice were mated with adult males. In the control and TP groups, all mice became pregnant on the first mating attempt. Their mating efficiency and fertility outcomes showed no significant difference. In the TP-loaded nanoparticle-treated mice, only one exhibited copulatory plug and became pregnant, but it did not successfully deliver (Table 3). Most mice appeared to be subfertile after TP-loaded nanoparticle administration.

\section{Ovarian histological manifestation and follicle cell apoptosis detection}

As presented in Figure 6, different stages of developing follicles were clearly observed in the control and TP groups. TP did not inhibit ovulation, as a distinct corpus luteum was found in both the control and TP groups. However, follicle development was suppressed in the TP-loaded nanoparticle group, and few corpus lutea were observed. Ovarian tissue was seriously damaged, with overt ovarian fibrosis and vacuolar changes. There were almost no TUNEL-positive follicle cells in the sections from the control and TP groups. By contrast,
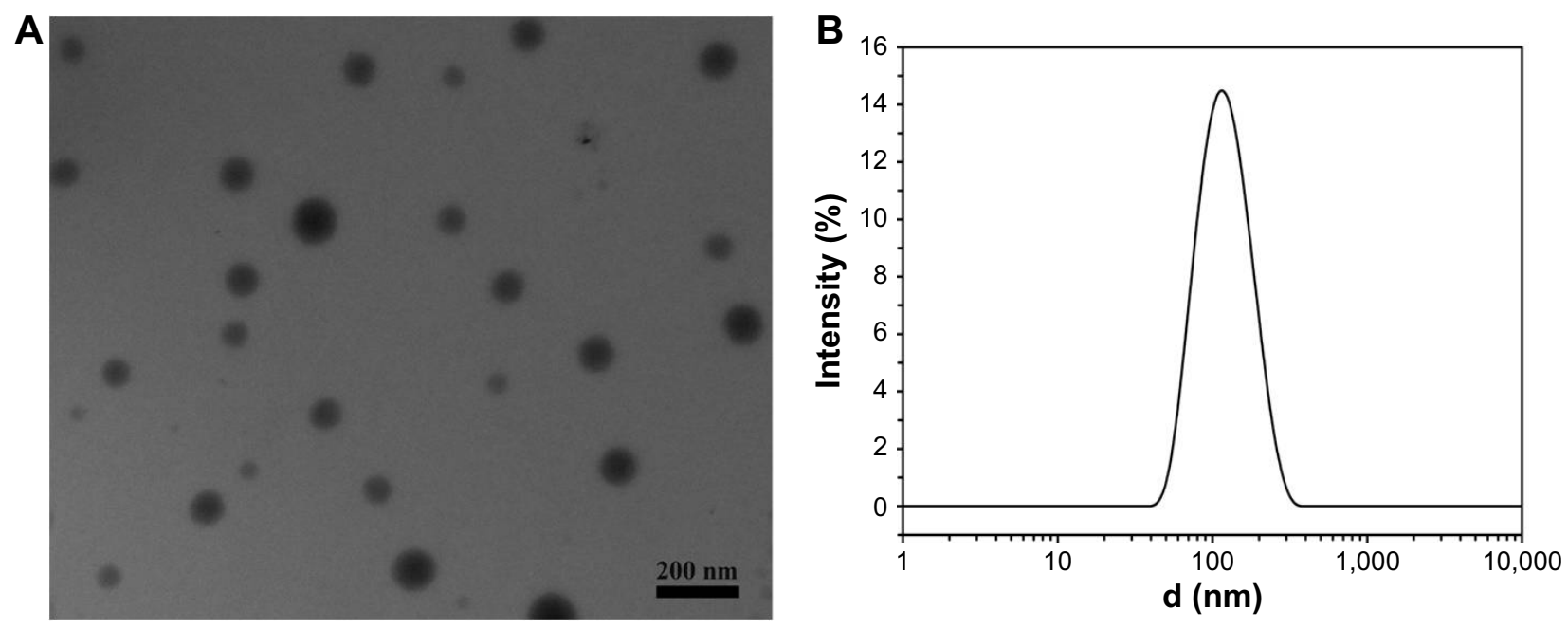

Figure 2 Transmission electron microscopy image of self-assembled micelles and dynamic light scattering curve of micelle aqueous solution. Notes: (A) Transmission electron microscopy image of self-assembled micelles; (B) dynamic light scattering curve of micelle aqueous solution. 

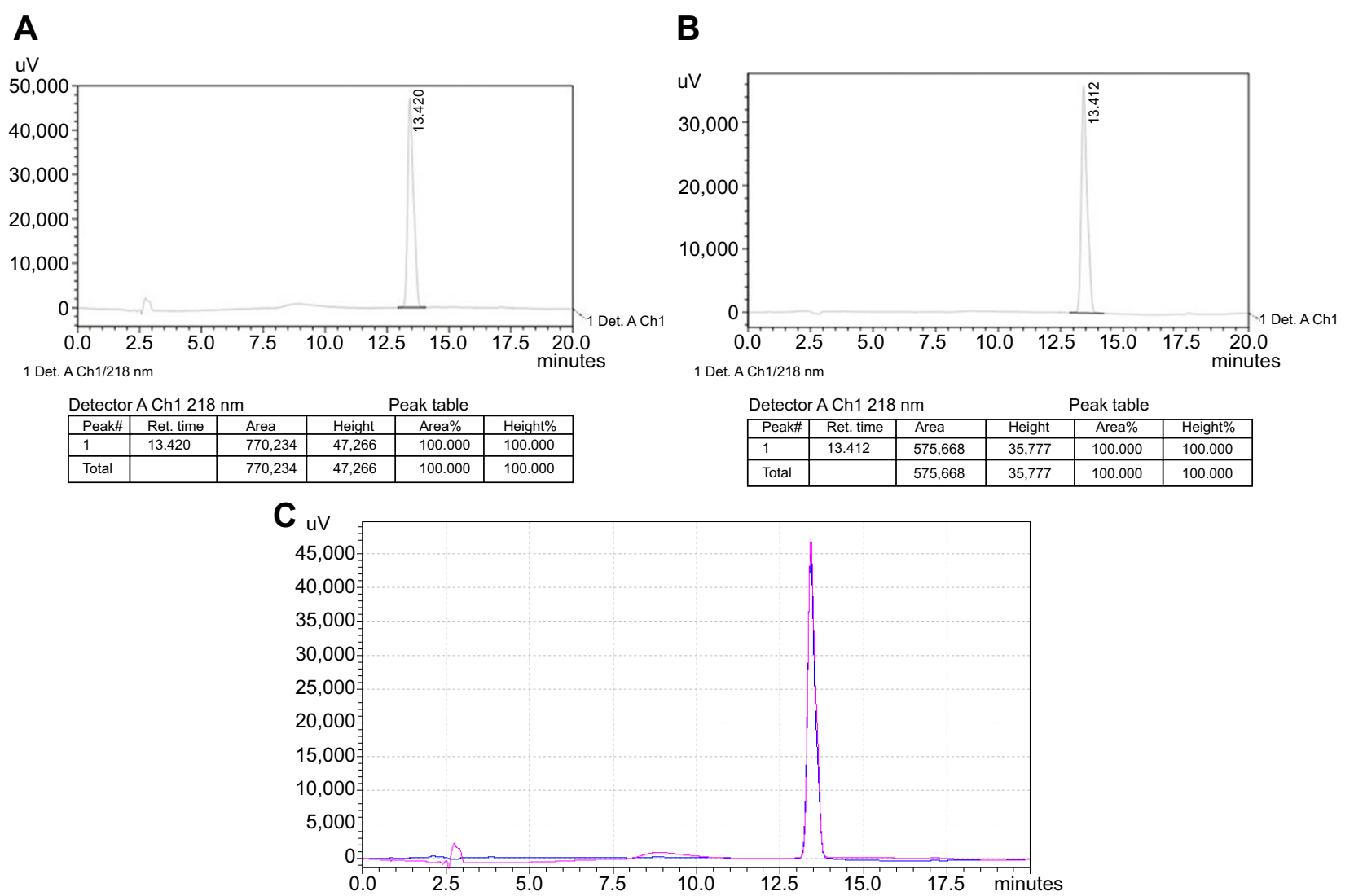

Figure 3 Spectra of high-performance liquid chromatography.

Notes: (A) TP standard, (B) TP-loaded nanoparticles, (C) overlay of the TP standard and TP-loaded nanoparticle spectra. Pink: TP standard; blue: TP-loaded nanoparticles. In addition, $20 \mu \mathrm{L}$ of TP standard and TP-loaded nanoparticles was used for high-performance liquid chromatography detection, as the two figures matched quite well; this means that TP was not changed during the TP-loaded nanoparticle production.

Abbreviation: TP, triptolide.

TUNEL-positive follicle cells were abundant in the TP-treated mice (Figure 7). Thus, TP-loaded nanoparticle treatment significantly induced developing follicle apoptosis.

\section{Discussion}

In recent years, several novel drug delivery systems have been used as carriers to enhance TP bioavailability and to reduce its toxicity. ${ }^{11,12}$ These targeted delivery systems can work in two ways: via passive or active targeting. The major advantage of passive targeting is its ability to accumulate drug in the tumor tissues through the enhanced permeability and retention effect. ${ }^{13}$ The idea of revival of the abandoned anticancer drug by nanoparticle carrier could help to renew the clinical potential of abandoned therapeutics. ${ }^{14}$ In contrast, in active targeting, a specific drug is delivered utilizing the principle of ligand-receptor recognition. ${ }^{15}$ In this study, we developed a novel, actively targeted drug delivery system, TP-loaded nanoparticles, modified by FSH- $\beta$ peptide, and showed the potential of this system to establish a mouse model of POI. The high affinity of FSH- $\beta-(33-53)$ to FSHR has been shown by its potential to facilitate the access of paclitaxel carried by nanoparticles to ovarian tumor tissues expressing FSHR. ${ }^{16}$ FSH- $\beta$ - $(33-53)$ was chosen as a target-specific ligand due to its low immunogenicity and its small MW. The covalent coupling of FSH- $\beta$ and nanoparticles was successfully achieved via the sulfydryl group of FSH- $\beta$ and the maleimide group of Mal-PEG-b-PLA. The solubility of TP was enhanced by means of entrapment into

Table I The characteristics of TP-loaded nanoparticles

\begin{tabular}{llllll}
\hline & Diameter $(\mathbf{n m})$ & PDI & Zeta potential $(\mathbf{m V})$ & DL $(\%)$ & EE $(\%)$ \\
\hline TP-loaded nanoparticles & $111.73 \pm 0.901$ & $0.117 \pm 0.0035$ & $-10.667 \pm 0.32$ & $3.33 \%$ & $99.62 \%$ \\
\hline
\end{tabular}

Note: The data were repeated three times (mean \pm standard deviation; number $=3$ ).

Abbreviations: TP, triptolide; PDI, polydispersity index; DL, drug-loading efficiency; EE, encapsulation efficiency. 
Table 2 The number of deaths observed after single doses of TP-loaded nanoparticles and TP administered intravenously in mice for 14 days

\begin{tabular}{|c|c|c|c|c|c|c|}
\hline Group & Dose (mg/kg) & $\begin{array}{l}\text { Total number } \\
\text { of mice }\end{array}$ & Number of deaths & Mortality (\%) & $L_{50}(\mathrm{mg} / \mathrm{kg})$ & 95\% credibility \\
\hline \multirow[t]{5}{*}{ TP } & 0.51 & 10 & 0 & 0 & 0.837 & $0.740-0.952$ \\
\hline & 0.64 & 10 & 2 & 20 & & \\
\hline & 0.80 & 10 & 5 & 50 & & \\
\hline & 1.00 & 10 & 6 & 60 & & \\
\hline & 1.25 & 10 & 10 & 100 & & \\
\hline \multirow[t]{5}{*}{ TP-loaded nanoparticles } & 0.80 & 10 & 0 & 0 & $\mathrm{I} .364$ & $1.219-1.540$ \\
\hline & 1.00 & 10 & I & 10 & & \\
\hline & 1.25 & 10 & 4 & 40 & & \\
\hline & 1.56 & 10 & 6 & 60 & & \\
\hline & 1.95 & 10 & 10 & 100 & & \\
\hline
\end{tabular}

Note: $\mathrm{Th}_{50}$ value of TP-loaded nanoparticles was $63 \%$ higher than that of TP.

Abbreviations: $T P$, triptolide; $L_{50}$, lethal median dose.

the amphiphilic diblock copolymer of PLA nanoparticles with an EE of nearly $100 \%$.

Because of the increased incidence of POI and the infertility it causes, it has become critical to develop a better model of POI. We tried to take advantage of the side effects of TP on the female reproductive system to induce an ideal animal model of POI. TP-loaded nanoparticles were synthesized to reduce its severe toxicity toward the gastrointestinal tract, kidney, liver, and other organs. In the acute toxicity study, TP exhibited severe toxicity and mortality, and the $\mathrm{LD}_{50}$ value was extremely low. In contrast, the $\mathrm{LD}_{50}$ value of TP-loaded nanoparticles increased progressively and was 63\% higher than that of TP. This test indicated that it was safer to utilize TP-loaded nanoparticles. Nevertheless, the research to reduce the toxicity of TP should be continued.

POI is defined as the cessation of ovarian function prior to the age of 40 years. ${ }^{17}$ It involves hypergonadotropic hypogonadism, increasing symptoms of estrogen deficiency and

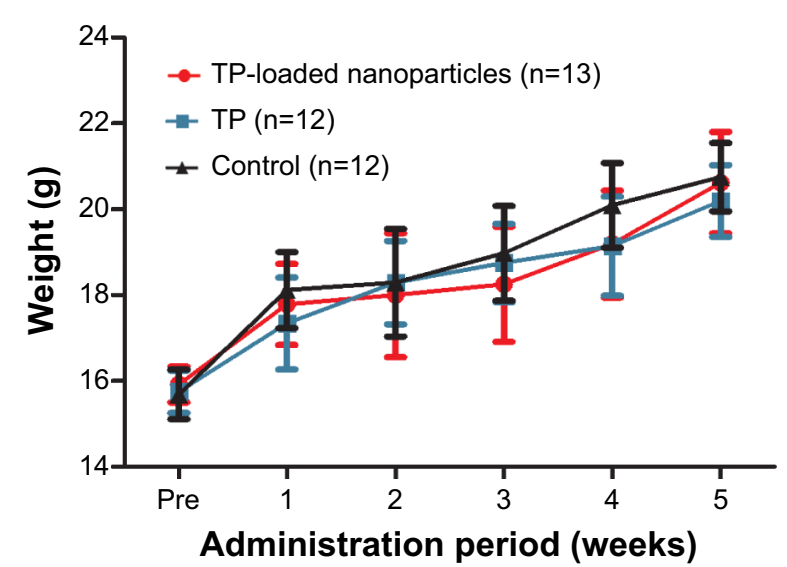

Figure 4 Body weight before and during the administration period (mean \pm standard deviation).

Abbreviations: TP, triptolide; $n$, number. subfertility. To evaluate whether the mice treated with TPloaded nanoparticles were suitable as a POI animal model, serum AMH was measured because it is not influenced by the estrous cycle. ${ }^{18}$ The lower serum AMH in TP-loaded nanoparticle-treated mice indicated decreased ovarian function. AMH is mainly produced by the granulosa cells in small antral follicles, and AMH measurement is a far more sensitive marker of diminished ovarian reserve than traditional markers such as early-follicular-phase FSH or estradiol. ${ }^{19}$ Ovarian histomorphology revealed that atrophied ovaries of TP-loaded nanoparticle-treated mice were mostly composed of fibrous interstitial tissue and many collapsed oocytes. The ovarian structures were significantly destroyed, and the development follicles and corpus luteum had disappeared. In addition, we tried to use the in situ cell death detection kit to help detect follicle apoptosis as an in situ method for detecting areas of DNA that are nicked during apoptosis, and follicle apoptosis was commonly observed in TP-loaded

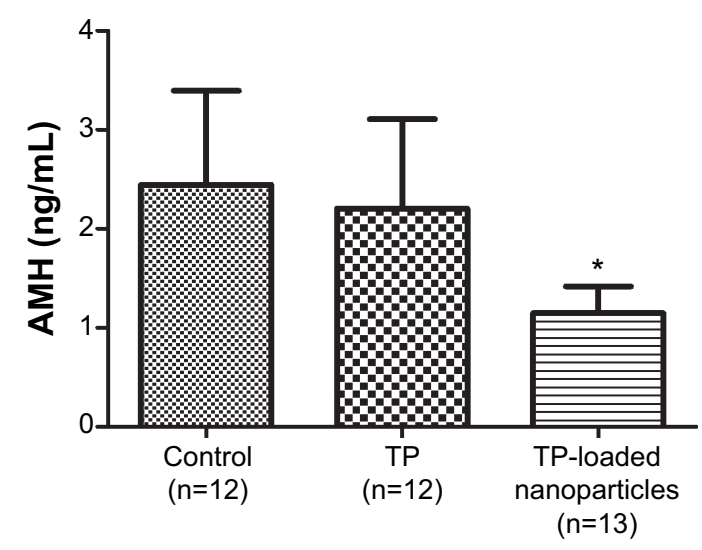

Figure 5 The comparison of serum AMH levels in the different groups (mean \pm standard deviation).

Note: $* P<0.01$ compared with the control group and TP group.

Abbreviations: $\mathrm{AMH}$, antimullerian hormone; $\mathrm{n}$, number; TP, triptolide. 
Table 3 Mating efficiency and fertility outcome

\begin{tabular}{llll}
\hline & Control $(\mathbf{n}=\mathbf{6})$ & TP $(\mathbf{n}=\mathbf{6})$ & TP-loaded nanoparticles $(\mathbf{n}=\mathbf{l} \mathbf{3})$ \\
\hline N of pregnancies & 6 & 6 & $I^{*}$ \\
Pregnancy rate (\%) & 100 & 100 & $7.69^{*}$ \\
Time of gestation (days) & $3 \pm 1.53$ & $3.67 \pm 1.37$ & 2 \\
$\mathrm{~N}$ of births & 6 & 6 & $0 *$ \\
Birth rate (\%) & 100 & 100 & $0 *$ \\
$\mathrm{~N}$ of fetuses & $10.33 \pm 1.97$ & $8.17 \pm 1.72$ & - \\
\hline
\end{tabular}

Note: $* P<0.01$ compared with the control group and TP group.

Abbreviations: $n$, number; TP, triptolid.

nanoparticle-treated mice. More important, only one mouse in the TP-loaded nanoparticle group was pregnant, but she miscarried, showing that subfertility was prevalent.

Any reason induced exhaustion of primordial follicles pool and destruction of ovarian structures could cause POI. Maintenance of the development of primordial follicles into developing follicles is crucial for ovarian function throughout women's reproductive life; thus, diversiform animal models have been established for further study about this disease. Genetically modified mice might provide information about genetic abnormalities that lead to accelerated activation of primordial follicles and subsequent premature exhaustion of the follicle pool, resulting in estradiol deficiency and infertility. ${ }^{20-22}$ Chemotherapy-induced POI rodent models and autoimmune POI models were developed and commonly applied in the research of the treatment of gonadal dysfunction with cytotoxic drugs and autoimmune ovarian damage. ${ }^{23,24}$ However, the etiology and mechanism of POI are unknown in most cases. As research on the pharmacological spectrum of traditional Chinese medicine accumulates, and since these medicines are more widely application in the clinic, the side effects of Chinese patent medicines or extracts of Chinese medicines on the reproductive system have received much attention. ${ }^{5} \mathrm{TP}$ is one of these promising extracts of the traditional Chinese medicine TWHF. Treatment with $0.4 \mathrm{mg} / \mathrm{kg}$ of TP for 3 months can significantly reduce serum $\mathrm{E}_{2}$ and $\mathrm{P}$, and increase FSH and $\mathrm{LH} .{ }^{5}$ Moreover, it has a direct effect on the ovaries, with a reduction in developing follicles and an increase in atretic follicles in treated rats. Nevertheless, a long period of TP treatment can cause serious toxicity toward other systems,
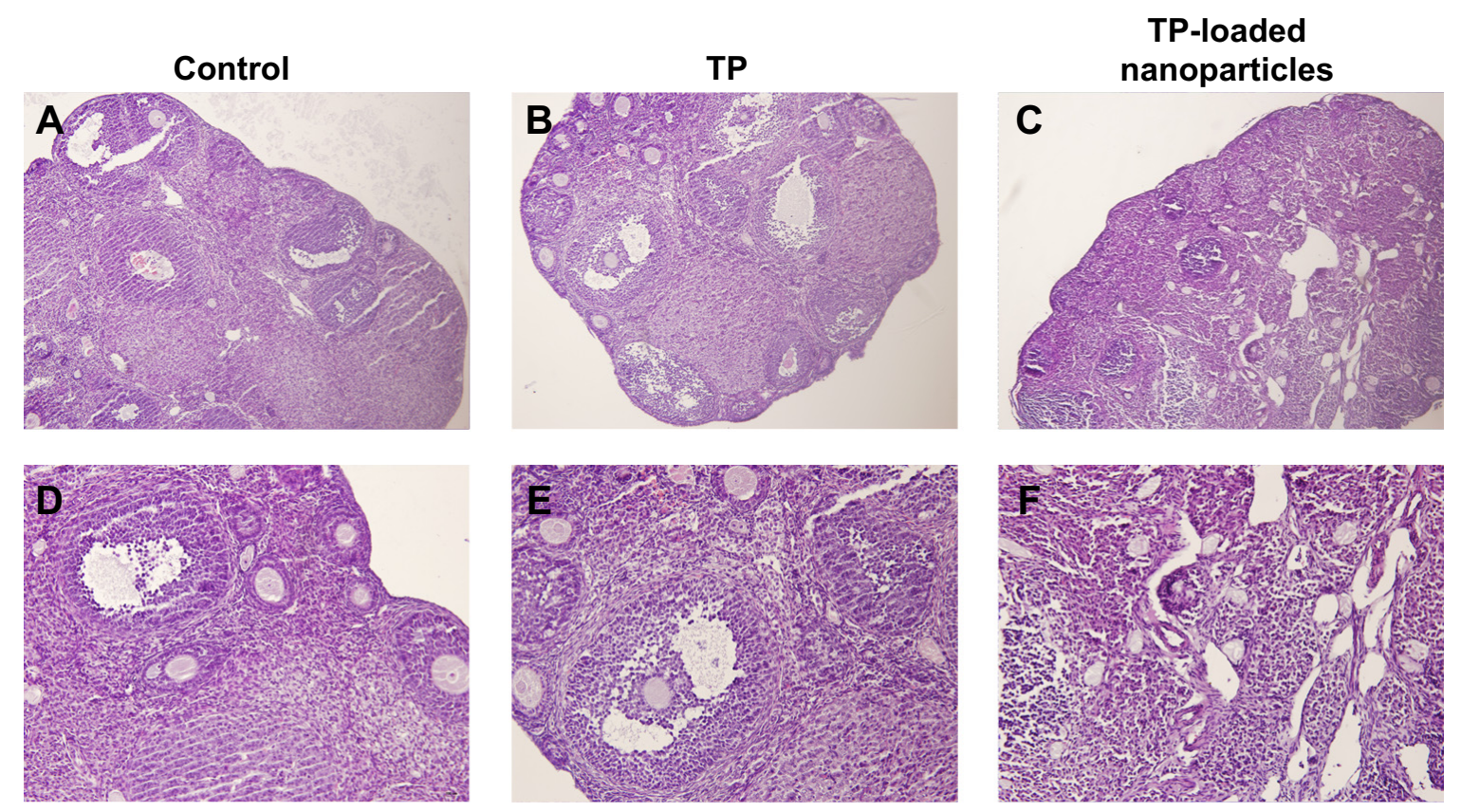

Figure 6 The changes in ovarian histomorphology in the three groups.

Notes: $(\mathbf{A}-\mathbf{C})$ : hematoxylin and eosin $\times 100$; (D-F): hematoxylin and eosin $\times 200$. Different stages of developing follicles and distinct corpus luteum were clearly observed in the control and TP groups. Follicle development was suppressed in the TP-loaded nanoparticle group, and few corpus lutea were observed. Ovarian tissue was seriously damaged, with overt ovarian fibrosis and vacuolar changes.

Abbreviation: TP, triptolide. 


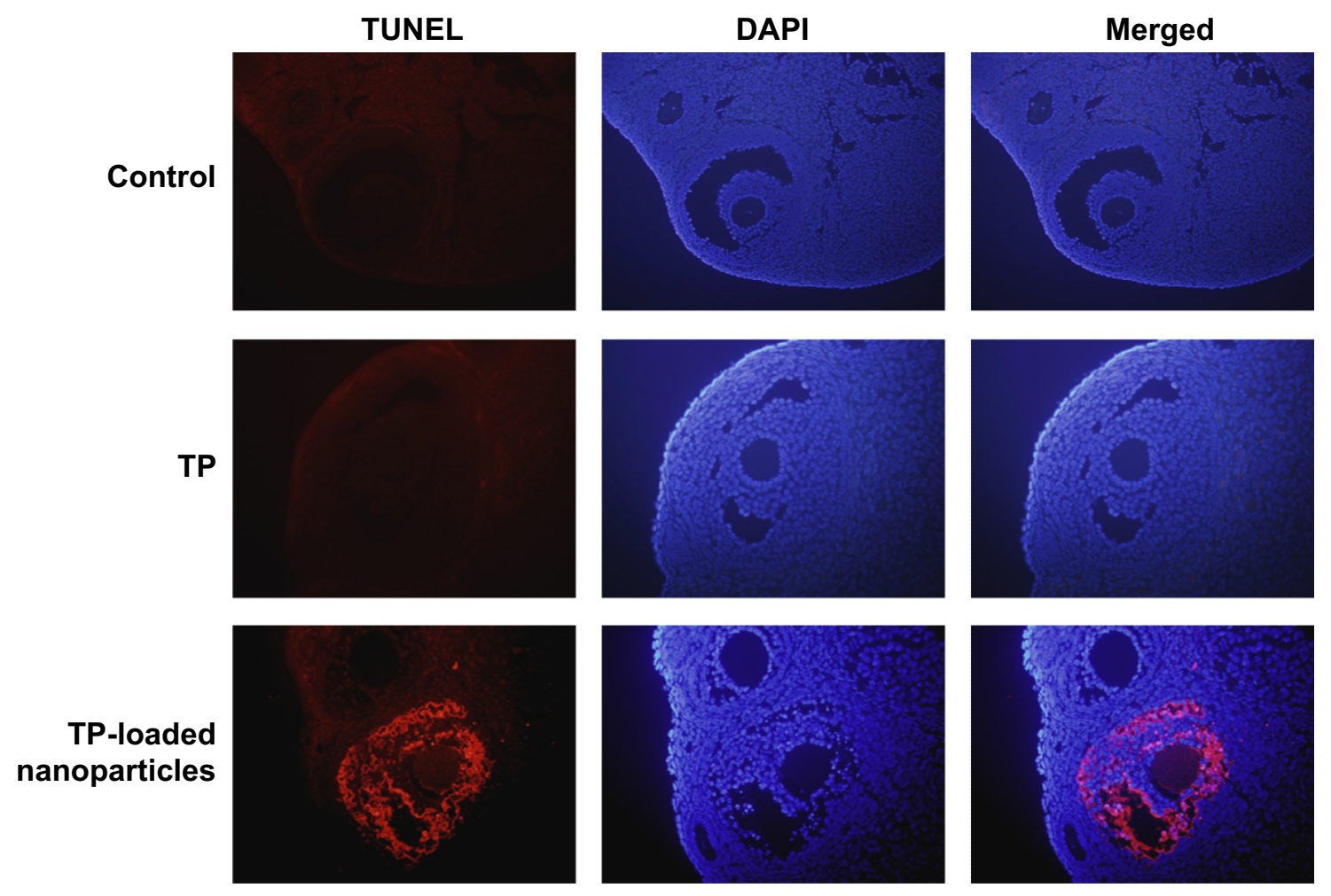

Figure 7 Detection of follicle cell apoptosis by TUNEL assay $(\times 400)$.

Abbreviations: TUNEL, terminal deoxynucleotidyl transferase dUTP nick end labeling; DAPI, 4',6-diamidino-2-phenylindole; TP, triptolide.

and the application of this animal model was possibly limited by its 3-month experimental cycle. We designed the current actively targeted drug delivery system to improve the efficiency and specificity of drug delivery. As our data show, the mouse model induced by TP-loaded nanoparticles displayed an impaired ovarian structure, decreased serum AMH, subfertility, and increased follicle apoptosis, which were similar to the manifestations of POI in humans. The administration period of TP was significantly shorted by using TP-loaded nanoparticles, and the toxicity of TP was also decreased by targeted delivery. The fertility evaluation was only monitored in 15 days after the cessation of dosing, so subfertility induced by TP-loaded nanoparticles may be reversible because follicles can grow from the undamaged primordial pool reserve, which is the imperfection of drug-induced POI animal models. In any case, TP-loaded nanoparticles are an efficient drug delivery system and may still serve as a candidate to create a novel POI mouse model, which could mimic the manifestations of POI in humans.

\section{Conclusion}

In this study, FSH- $\beta$-modified nanoparticles containing TP were developed to ensure specific delivery of TP into the targeted organ, the ovary. Acute toxicity analysis suggested that TP-loaded nanoparticles lowered the toxicity of TP with a higher $\mathrm{LD}_{50}$ value. In addition, the mice treated with TP-loaded nanoparticles displayed decreased serum AMH, impaired ovarian structure and function, subfertility, and increased follicle apoptosis. All these features were similar to the manifestations of women who suffer from POI. It appears that TP-loaded nanoparticles have the potential to induce a novel mouse model of POI.

\section{Acknowledgments}

This work was supported by National Natural Science Foundation of China (81471423) and Shanghai Municipal Committee of Science and Technology Project (14ZR1404200).

\section{Disclosure}

The authors report no conflicts of interest in this work.

\section{References}

1. Nie J, Zhou M, Lü C, et al. Effects of triptolide on the synaptophysin expression of hippocampal neurons in the $\mathrm{AD}$ cellular model. Int Immunopharmacol. 2012;13(2):175-180.

2. Liu Q. Triptolide and its expanding multiple pharmacological functions. Int Immunopharmacol. 2011;11(3):377-383.

3. Xin MJ, Cui SH, Liu S, et al. Triptolide prolonged allogeneic islet graft survival in chemically induced and spontaneously diabetic mice without impairment of islet function. Hepatobiliary Pancreat Dis Int. 2010;9(3) $312-318$. 
4. Chen X, Chen SL. A woman with premature ovarian failure induced by Tripterygium wilfordii Hook.f. gives birth to a healthy child. Fertil Steril. 2011;96(1):e19-e21.

5. Liu J, Jiang Z, Liu L, et al. Triptolide induces adverse effect on reproductive parameters of female Sprague-Dawley rats. Drug Chem Toxicol. 2011;34(1):1-7.

6. Zhang J, Jiang Z, Mu X, Wen J, Su Y, Zhang L. Effect of triptolide on progesterone production from cultured rat granulosa cells. Arzneimittelforschung. 2012;62(6):301-306.

7. Zhang J, Liu L, Mu X, Jiang Z, Zhang L. Effect of triptolide on estradiol release from cultured rat granulosa cells. Endocr J. 2012;59(6):473-481.

8. Wadia PR, Mahale SD, Nandedkar TD. Effect of the human folliclestimulating hormone-binding inhibitor and its N-terminal fragment on follicle-stimulating hormone-induced progesterone secretion by granulosa cells in vitro. J Biosci. 2007;32(6):1185-1194.

9. Agris PF, Guenther RH, Sierzputowska-Gracz H, et al. Solution structure of a synthetic peptide corresponding to a receptor binding region of FSH (hFSH-beta 33-53). J Protein Chem. 1992;11(5):495-507.

10. Zhou ZL, Yang YX, Ding J, Li YC, Miao ZH. Triptolide: structural modifications, structure-activity relationships, bioactivities, clinical development and mechanisms. Nat Prod Rep. 2012;29(4):457-475.

11. Zheng S, Löw K, Wagner S, Yang X, von Briesen H, Zou S. Cytotoxicity of Triptolide and Triptolide loaded polymeric micelles in vitro. Toxicol In Vitro. 2011;25(8):1557-1567.

12. Mei Z, Li X, Wu Q, Hu S, Yang X. The research on the anti-inflammatory activity and hepatotoxicity of triptolide-loaded solid lipid nanoparticle. Pharmacol Res. 2005;51(4):345-351.

13. Reish K. Enhanced permeability and retention of macromolecular drugs in solid tumors: a royal gate for targeted anticancer nanomedicines. J Drug Target. 2007;15(7-8):457-464.

14. Karve S, Werner ME, Sukumar R, et al. Revival of the abandoned therapeutic wortmannin by nanoparticle drug delivery. Proc Natl Acad Sci U S A. 2012;109(21):8230-8235.
15. Zhao X, Li H, Lee RJ. Targeted drug delivery via folate receptors. Expert Opin Drug Deliv. 2008;5(3):309-319.

16. Zhang XY, Chen J, Zheng YF, et al. Follicle-stimulating hormone peptide can facilitate paclitaxel nanoparticles to target ovarian carcinoma in vivo. Cancer Res. 2009;69(16):6506-6514.

17. Maclaran K, Horner E, Panay N. Premature ovarian failure: long-term sequelae [J]. Menopause Int. 2010;16(1):38-41.

18. Tsepelidis S, Devreker F, Demeestere I, Flahaut A, Gervy Ch, Englert Y. Stable serum levels of anti-Müllerian hormone during the menstrual cycle: a prospective study in normo-ovulatory women. Hum Reprod. 2007;22(7):1837-1840.

19. Tremellen KP, Kolo M, Gilmore A, Lekamge DN. Anti-mullerian hormone as a marker of ovarian reserve. Aust N Z J Obstet Gynaecol. 2005;45(1):20-24.

20. Reddy P, Liu L, Adhikari D, et al. Oocyte-specific deletion of Pten causes premature activation of the primordial follicle pool. Science. 2008;319(5863):611-613

21. Castrillon DH, Miao L, Kollipara R, Horner JW, DePinho RA. Suppression of ovarian follicle activation in mice by the transcription factor Foxo3a. Science. 2003;301(5630):215-218.

22. Rajkovic A, Pangas SA, Ballow D, Suzumori N, Matzuk MM. NOBOX deficiency disrupts early folliculogenesis and oocyte-specific gene expression. Science. 2004;305(5687):1157-1159.

23. Ghadami M, El-Demerdash E, Zhang D, et al. Bone marrow transplantation restores follicular maturation and steroid hormones production in a mouse model for primary ovarian failure. PLoS One. 2012;7(3):e32462.

24. Tang CL, Li F, Sun L, Li DJ. Therapeutic effect of Bushen Huoxue recipe on autoimmune premature ovarian failure mice established by immunization with recombinant porcine zona pellucida 4 antigen. Chin J Integr Med. 2013;19(6):439-445.
International Journal of Nanomedicine

\section{Publish your work in this journal}

The International Journal of Nanomedicine is an international, peerreviewed journal focusing on the application of nanotechnology in diagnostics, therapeutics, and drug delivery systems throughout the biomedical field. This journal is indexed on PubMed Central, MedLine, CAS, SciSearch ${ }^{\circledR}$, Current Contents ${ }^{\circledR} /$ Clinical Medicine,

\section{Dovepress}

Journal Citation Reports/Science Edition, EMBase, Scopus and the Elsevier Bibliographic databases. The manuscript management system is completely online and includes a very quick and fair peer-review system, which is all easy to use. Visit http://www.dovepress.com/ testimonials.php to read real quotes from published authors. 